\title{
openaccess
}

\section{Immersive Virtual Reality as a teaching aid for anatomy}

\author{
Laura Mason (1) 0000-0002-9679-7063 and Marc Holmes (1) 0000-0002-8206-5451 \\ Swansea University \\ Corresponding author: L.Mason@swansea.ac.uk
}

Anatomy is a discipline where students are required to identify structures of the human body. It is typically a topic which challenges students due to the large volume of terms and content they are required to understand. This study was designed to investigate whether Virtual Reality (VR) as an innovative approach to teaching could improve both student experience and attainment in this subject area. A specifically developed VR platform was created in which Medical Engineering students $(\mathrm{N}=42)$ were asked to individually compete to assemble a human skeleton in both the fastest time and with the fewest errors. This gamification in an immersive environment was hypothesised to increase students' understanding and retention of anatomical information and was compared to studying from a set of traditional notes. The results showed a $10 \%$ greater improvement in test scores with VR over the use of notes (non-significant, $P=0.141$ ). In the longer term those who participated in the study performed significantly better on the end of module examination $(P=0.012)$ suggesting measurable learning gain from the experience more widely. Students responded positively to the use of VR in this context and expressed an interest in seeing more VR as part of their anatomy education and their Higher Education experience more broadly.

\section{Introduction}

Human anatomy is a branch of biology where the human body is studied in terms of its structural organization (VanPutte, Regan, \& Russo, 2014). Whilst commonly thought of as a medical expertise, knowledge of the structures of the human body and the spatial relationships between them is essential for understanding and practical application in a number of educational areas, including Nursing and Allied Health Care, Sports Sciences, Biosciences and Medical Engineering (Johnston, 2010; Wright, 2012; Nicholson, Reed, \& Chan, 2016). In medical schools worldwide, anatomy has traditionally been taught using dissection of human cadavers (Sugand, Abrahams, \& Khurana, 2010) however this is no longer used as the principle delivery method, largely due to complexity and costs associated with availability, and, safe storage of cadavers (McLachlan \& Patten, 2006; Wright, 2012).

It seems logical for students to contextualize 3D anatomical structures, anatomical education should allow students the 3D, multisensory interaction which would have been traditionally brought through dissection (Preece, Williams, Lam, \& Weller, 2013). Consequently a number of studies have investigated alternative teaching methods to enable students to gain spatial understanding of complex human structures, including body painting (McMenamin, 2008; Nanjundaiah \& Chowdaporkar, 2012), the use of three-dimensional (3D) models (Vernon \& Peckham, 2002; Preece et al., 2013; Lim, Loo, Goldie, Adams, \& McMenamin, 2016) and 3D computer based images (Levinson, Weaver, Garside, McGinn, \& Norman, 2007; Preece et al., 2013;

\section{Correspondence}

Laura Mason (L.Mason@swansea.ac.uk)

doi: 10.1255/vrar2018.ch6

Citation: L. Mason and M. Holmes, "Immersive Virtual Reality as a teaching aid for anatomy", in Proceedings of the Virtual and Augmented Reality to Enhance Learning and Teaching in Higher Education Conference 2018, Ed by J. Hudson and R. Kerton. IM Publications Open, Chichester, pp. 49-60 (2019). https://doi.org/10.1255/vrar2018.ch6

\section{(c) 2019 The Authors}

This licence permits you to use, share, copy and redistribute the paper in any medium or any format provided that a full citation to the original paper is given.

Print ISBN: 978-1-906715-30-4 Online ISBN: 978-1-906715-28-1 
Webster, 2015; Peterson \& Mlynarczyk, 2016). Findings from these studies have been mixed with some evidencing improved learning (Hackett \& Proctor, 2016) and others finding little (Codd \& Choudhury, 2011), or even negative (Levinson et al., 2007) effect on learning. Khot, Quinlan, Normand, and Wainman (2013) sought to compare the effectiveness of a plastic model, a static computer-based model and a VR computer-based model on students learning of pelvic anatomy. They found that both forms of computer-based model were inferior to the 3D plastic model for students' learning and suggested that this may be related to students' cognitive load (Sweller, 1994) during computer-based learning.

Consistent with the advancement in the study of anatomy, the evolution of VR in an educational setting is largely attributable to advances in clinical medical training (Satava, 1993). Alongside the development of flight simulators (Loftin, Wang, Baffes, \& Hua, 1988) the area of surgical simulation has been a driving force in the development of $V R$ environments where students can be immersed and interact to develop competence in a safe but realistic environment (Seymour et al., 2002; Hariri, Rawn, Srivastava, Youngblood, \& Ladd, 2004; Botezatu, Hult, Tessma, \& Fors, 2010). Immersive VR refers to a VR environment where real-world surroundings are replaced with an artificial environment in which users can suspend reality and fully engage with the created environment. Typically, this is done using a head mounted display and differs significantly from computer-based systems frequently described as VR in the literature (Seymour et al., 2002; Levinson et al., 2007; Codd \& Choudhury, 2011). Burdea and Coiffet (2003) list the main features of VR as immersion, interaction and imagination.

A 2014 meta-analysis by Merchant, Goetz, Cifuentes, Keeney-Kennicutt, and Davis investigates the effectiveness of VR based instruction on students' learning outcomes. They conclude that while simulations and virtual worlds are shown to be effective, students' performance is enhanced most when they conduct individual games in VR, and, that students are able to retain their knowledge beyond short-term learning in this way.

Therefore, the aims of this study were threefold;

1. We aimed to develop a tailored VR task with elements of gamification to allow students to explore the human skeleton in an immersive environment.

2. We investigated the potential learning gain from completing the VR task in both the short- and longerterm and its effects on student attainment.
3. We aimed to gather student's opinions on the VR task and the use of VR as part of their higher education experience more widely.

\section{Aim 1: Application development Hardware design choices}

From our prior training, three possible choices were considered:

1. Google Cardboard 3 Degree Of Freedom (3DoF) VR headset.

2. Mobile phone Augmented Reality (AR) via Vuforia 6 Degree Of Freedom (6DoF) handheld AR.

3. Room-scale VR via a HTC Vive on SteamVR 6 Degree Of Freedom (6DoF)VR headset and $2 \times 6$ DoF controllers.

There were 3 main aspects to consider in selecting hardware: controls, available computer power and price. Each is summarized in Table 1 in relation to the available options.

Our decision was to opt for a room-scale VR kit (HTC Vive). This set-up was the most suitable to allow for full 3D understanding due to its unrestricted head movements and the wide range of gamification elements possible with 2 6DoF VR controllers.

\section{Software}

The software solution options were:

1. Build our own VR engine;

2. Unity3D, and,

3. Unreal Engine.

As there were time constraints surrounding this project, we did not have time to build our own VR engine thus the existing commercial options remained.

Unity3D and Unreal have two different price models; Unity3D has a paid-per-developer seat and Unreal has a percentage of income model. While both Unity and Unreal have terms under which they can be used for non-commercial applications, these specify that applications must be educating the students in Unity or Unreal use and development; this does not apply to this project as it is part of the standard education of anatomy and will not teach the students about Unity or Unreal. There are also plans to use the application for advertising of the University course and possible subsequent commercial sale. Unity3D provided a standard price, whereas the Unreal percentage model 
Table 1. Comparisons of hardware choices for VR anatomy app.

\begin{tabular}{|c|c|c|c|}
\hline & Controls & Power & Price \\
\hline $\begin{array}{l}\text { Google } \\
\text { Cardboard }\end{array}$ & $\begin{array}{l}\text { Limited head movement } \\
\text { (3DoF). } \\
\text { Single input. } \\
\text { This severely limits the } \\
\text { range of movement there- } \\
\text { fore restricting the viewing } \\
\text { capabilities and manipulation } \\
\text { of the bones for observation } \\
\text { and gamification benefits. }\end{array}$ & $\begin{array}{l}\text { Google Cardboard runs on } \\
\text { mobile chipsets found in } \\
\text { smartphones, which have } \\
\text { low processing power. }\end{array}$ & $\begin{array}{l}\text { Google Cardboard pro- } \\
\text { vides a cheap option as a } \\
\text { "bring your own device" } \\
\text { (BYOD) format can be } \\
\text { used since the majority } \\
\text { of students own their } \\
\text { devices. } \\
10 \% \text { needs to be } \\
\text { covered by university } \\
\text { devices ( } £ 300 \text { to } £ 500 \\
\text { per smartphone; Filer \& } \\
\text { Holmes, 2018). }\end{array}$ \\
\hline $\begin{array}{l}\text { Augmented } \\
\text { Reality (AR) }\end{array}$ & $\begin{array}{l}\text { Touch controls on the } \\
\text { screen. } \\
\text { The limitation on movement } \\
\text { is the visibility of the tracking } \\
\text { target by the phone. } \\
\text { It does have access to the } \\
\text { multi-touch screen to enable } \\
\text { interaction with models } \\
\text { (bones) and allows manipula- } \\
\text { tion of the models such as } \\
\text { moving, pinching and clicking. }\end{array}$ & $\begin{array}{l}\text { Mobile phone AR runs on } \\
\text { mobile chipsets found in } \\
\text { smartphones, which have } \\
\text { low processing power. }\end{array}$ & $\begin{array}{l}\text { Mobile phone AR pro- } \\
\text { vides a cheap option as a } \\
\text { "bring your own device" } \\
\text { (BYOD) format can be } \\
\text { used since the majority } \\
\text { of students own their } \\
\text { devices. } \\
10 \% \text { needs to be covered } \\
\text { by university devices } \\
\text { ( } £ 300 \text { to } 500 \text { per smart } \\
\text { phone) }\end{array}$ \\
\hline HTC Vive & $\begin{array}{l}\text { HTC Vive with two control- } \\
\text { lers can move fully in 6DoF. } \\
\text { Each controller has a trigger, } \\
\text { a grip button, a menu button } \\
\text { and a touch pad. } \\
\text { 6DoF gives the ability to } \\
\text { manipulate the models com- } \\
\text { pletely without a freedom } \\
\text { constraint. However, the lack } \\
\text { of finger tracking means that } \\
\text { students would have to use } \\
\text { non-intuitive triggers and } \\
\text { buttons to interact with the } \\
\text { application. }\end{array}$ & $\begin{array}{l}\text { The HTC Vive is connected } \\
\text { to a PC, at the minimum rec- } \\
\text { ommend specification; this is } \\
\text { significantly more powerful } \\
\text { than the other options. } \\
\text { This was important as sig- } \\
\text { nificant processing power } \\
\text { was needed to render all the } \\
\text { detail of the skeletal struc- } \\
\text { tures to avoid oversimplifying } \\
\text { and reducing the available } \\
\text { information from which the } \\
\text { students could learn. }\end{array}$ & $\begin{array}{l}\text { HTC Vive costs } \sim £ 1500 \\
\text { per unit. }\end{array}$ \\
\hline
\end{tabular}


would be confusing if not highly expensive to apply to Higher Education courses.

For the user interaction, free Software Development kits were available in the form of both SteamVR kit and Virtual Reality Tool Kit (VRTK). The SteamVR example, while useful at a low level of programming, needed to be changed for our use, whereas VRTK had an assembly skeleton, object gripping, teleporting and user interfaces which could be quickly repurposed. VRTK also provided the option of switching to alternative room scale VR devices which were in development at the time of the start of this project such as the Oculus Rift Touch, or the later released Windows Mixed Reality.

\section{The anatomy data set}

The following options were considered:

1. Commission a photogrammetry scan of the bones;

2. Buy an artist's representation of the body from a 3D model site, and,

3. Use the Japanese life science database BodyParts3D.

The first method considered was to have a photogrammetry scan of the bones to get a highly accurate rendering of the human skeleton. After consultation with Alridge and Owen who work on the photogrammetry scans for digital Tudors (Owen, Boston, Aldridge, Johnston, \& Loe, 2016), it was apparent that, while the results could be very life-like, there were ethical concerns to overcome with the sourcing of the biological material and that the time required to photograph the body parts would amount to a full year of work.

The artistic representation is commonly sold for a variety of prices on stores such as Turbo Squid. The main advantage of this source is that they are already prepared for real time rendering, some even on smartphones, and may have animation already built in. The main disadvantage is that the models are not certified to be anatomically correct and are simplified (in many we found that small muscle groups were visibly missing or not separated).

The Japanese Life Science Database was recommended as it was already being used in the University's Medical School for creating 3D models. It is made up of a mixture of medical DICOM data and artistic rendering where the data is heavily detailed, making it suitable for our purpose. The main limitation with this selection is that the models are not computationally optimized. The skeleton alone is more than a million vertices, which will run well on a PC but would struggle to run on a mobile phone-it is
Creative Commons Attribution-ShareAlike 2.1 Japan (CC BY-SA 2.1 JP).

We ultimately chose to use the Japanese Life Science Database as it contains the appropriate level of detail, was available on open source and was free for use. Since we had already chosen the PC route we could cope with extra computational load provided by the finer detail of the database.

\section{Development within chosen tools}

In Unity the skeleton OBJ files were nested together under groups so that the breakdown of bones matched the course material (Figure 1). Those groups were given properties matching the VRTK example scenes so that they would snap to each other (this is known in the VRTK as snapping zones; Figure 2). An early request was to have bones assembled in any order and position, but after subsequently becoming aware about "fail faster" (Khanna, Guler, \& Nerkar, 2015) it was taken into consideration that the faster a mistake was made the sooner the student could start learning the correct method. For the benefit of encouraging students in this approach we chose for the part to highlight and snap the part into place only if the part was in the right place, in theory this reinforced the learning quickly.

For the identification of bones we opted for a multiplechoice system which appeared as a "?" sign pointing to the body, and, when touched, a list of options appeared

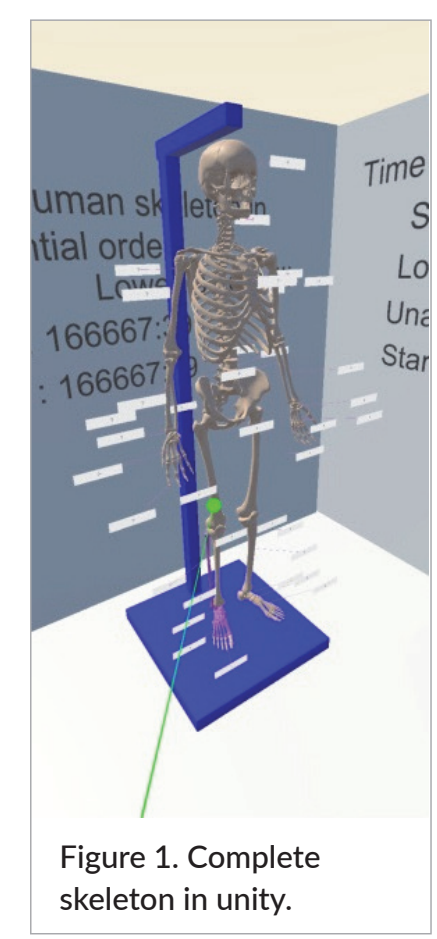




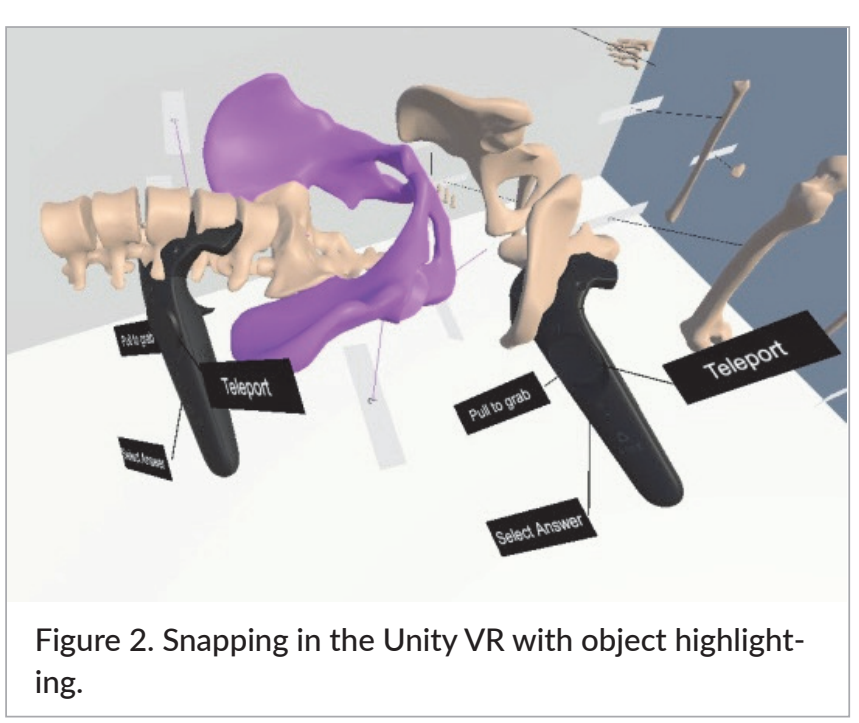

around the "?", normally containing 1 correct and 3 incorrect answers (Figure 3). If students chose the right answer the "?" was replaced with the correct answer and the background colour turned green; if the incorrect choice was made the background flashed red.

To encourage the students to complete all of the multiple-choice labelling questions, a timer was added (Figure 4) which stopped after all the model bones were attached and all the questions were answered, introducing a competitive element. To reduce random guessing in the multiple-choice questions, 30 seconds was added to the clock for choosing the incorrect labels. When the correct labels were selected 30 seconds were removed from the clock rewarding the students for the right answer. This allowed students to get a better time than they would otherwise, meaning that their score (final time) could be faster than their actual time therefore using a rewardbased rather than just a punishment system.

The initial aim of the project was to develop a VR platform which was fit for purpose. This process was assisted by user testing whenever we completed a new workable feature. The process of understanding user experience testing is explained by Norman (2002). VR presents some challenges with implementing all the key concepts of this process, such as affordances, signifiers, mapping, constraints, feedback and "conceptual model of a system" (Norman, 2002, p. 10). As VR devices are primarily visual and lack haptic feedback, it is difficult to cover all the psychological concepts mentioned in order to provide a realistic experience in all situations in VR. For example, in this context, "constraints" are hard to provide without limiting a range of motion. For example, students regularly cause bones to exist in the same space which either results in overlaying of parts or the bone to be knockedout of hand, rather than the more natural reaction force preventing this action. This is due to there being no force feedback to prevent the students from doing this, allowing this to mimic real life, this is a current challenge in VR. Also, there is no apparent weight in picking up an object such as a bone in VR. It is

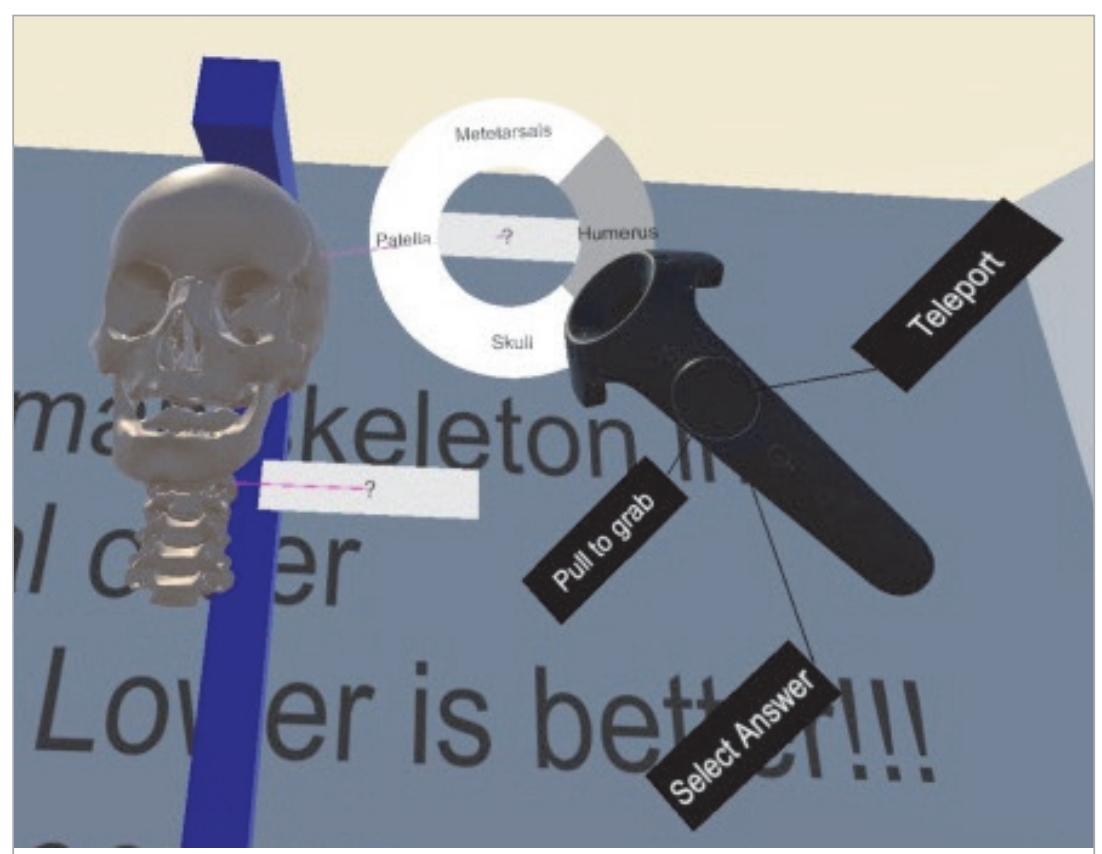

Figure 3. Multiple choice options. 


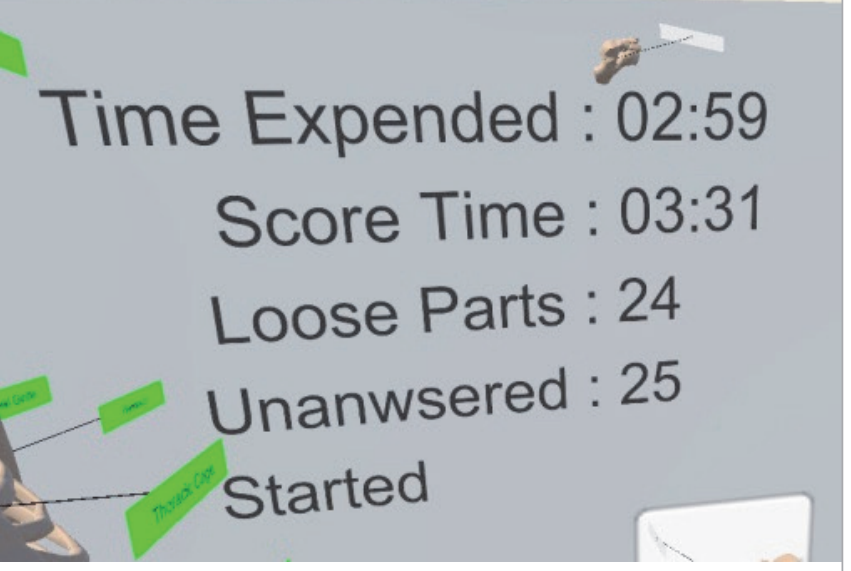

Figure 4. Timer for students to compete against.

still possible to clearly apply the "affordances" (grabbing, moving, snapping), "signifiers" (signs to grab), "feedback" (highlighting on touch, vibrating of touch, changing colours to indicate a correct answer).

This user experience testing is standard in computer development. It gave users the opportunity to find issues and where possible make changes. Post-graduate students were recruited to test the application. These students were recruited from two distinct groups-the first group was a collection of Sports Science/Biology/ Forensic Science students who have an existing knowledge of human anatomy. In contrast the second group comprised Materials Science students who had little or no knowledge of human anatomy. It was expected that the beginners would show us where the most essential areas of anatomy knowledge were required, whereas the students with expertise would show where our teaching methods differed from their conceptual model of the system for skeletal anatomy. To confirm our sampling, we included a simple pre- and post-test with multiple choice questions to test their knowledge of anatomy and to see if there was a measurable benefit from using the current development iteration of the anatomy application in VR. The User-Interface testing showed improvement in the pre- post-test, which steadily increased as improvements were made to the programme and the 12 iterations before it was finalised.

For this project we specified that the programme ran on a minimum hardware of intel is with 8 GB of RAM, AMD 480RX and a HDD drive. The University VR standard specification is an i5 4 core with $16 \mathrm{~GB}$ using a Nvidia 1070GTX, which is chosen on the grounds of being a high performance machine for 2016 (when the project began) and that after 5-6 year of Mores Law this specification will be closer to the general hardware the students may be purchasing themselves by 2021-2022.

\section{Methods (Aims 2 and 3) Participants}

The study participants were taken from a cohort of 42 first year undergraduate students studying Human Anatomy as a core module on a Medical Engineering degree scheme at a UK University. Study involvement was voluntary and not a summative assessment component of the module. As such, 9 students (21\%) chose to take part in the study. All participants provided written informed consent after receiving information about the study. The study was outlined to students during a lecture, but the module lecturer was not aware which students had agreed to participate.

\section{Study design}

The study was a randomized crossover design where students completed an assessment of their knowledge of skeletal anatomy before and after using the virtual reality platform and before and after studying from a set of written notes in a randomized order. The testing for the study took place in week 8 of an 11-week teaching semester where students had covered module content around the skeletal system in weeks 3-5. The module was assessed via an end of module examination, which took place approximately 7 weeks after the testing for the study. Following completion of the module participants were asked to complete a questionnaire about their opinions of the VR anatomy platform and their attitudes towards the use of VR in Higher Education more broadly. This consisted of a combination of yes/no, multiple choice and open-ended questions.

\section{Procedures}

After College Research Ethics Committee approval was granted, the study was outlined to students during a lecture. On arrival at the testing session all participants completed a baseline (pre-test) multiple choice test to establish their existing knowledge of the human skeletal system. The test consisted of 20 questions (200 maximum score) and participants were not given feedback regarding their responses. Following this, participants were randomly allocated to complete either the VR 
anatomy platform task or to study from a set of written notes on the skeletal system for a 20-minute period. After completing this first task participants were then re-tested (mid-test) using a similar set of multiple choice questions before carrying out the second arm of the trial and repeating the test a final time (post-test).

\section{VR anatomy platform task}

The task assigned to participants in the VR anatomy platform was to assemble a human skeleton, beginning with the skull, from the series of bones which lay on the floor around them, in the virtual environment. The level of detail in the task was commensurate with the detail students were required to know on the module more widely so that some bones were grouped together rather than requiring individual identification and attachment (e.g. bones of the skull, individual vertebrae, carpals, tarsals, phalanges).

\section{Data analysis}

Initially all data was assessed for normality using the Shapiro-Wilk test. Given that all data was normally distributed, pre- mid- and post-trial test scores were analyzed using a one-way repeated-measures ANOVA. Independent samples T-tests were used to compare performance on the end of module examination between those students who had completed the VR platform and those who had not. Paired samples T-tests were used to compare students' performance on the Anatomy module against their performance on the remaining 5 modules completed during the same semester of teaching, as a measure of learning gain. Data is presented as mean ( \pm SD). Significance was set at $P<0.05$ and all data was analyzed using IBM SPSS Statistics (version 22.0). Questionnaire data was analysed using a combination of descriptive statistics and thematic analysis. Responses to yes/no and multiple choice questions were expressed as percentage values and open-ended questions were grouped into themes based on the nature of the response (positive or negative).

\section{Results \\ User testing}

There were number of issues found and consequently dealt with. The first issue was that the application was on an open plane; there were received reports of appre- hension following the openness within the VR application, so it was changed into a room with four walls. We started with participants using the grip button on the Vive controller pick up the bones. However, it was hard to explain how to touch this button and users often held the controller incorrectly in attempts to press the button. Therefore, we changed this to allow participants to use the trigger instead which solved the problem.

Initially we had no sensory feedback when users were touching the bones, so users did not realize when they were interacting with the bone models. This was simply resolved by adding a vibration feedback to the controller.

In the beginning the room was spaced out and students had to "teleport" in VR to get the bones, however this was found to be confusing to new VR users and was removed in favour of a room scale experience of $2 \mathrm{~m} \times 2 \mathrm{~m}$ where users physically moved around to place parts.

Early versions of the application had a game physics model simulating gravity and collisions; this resulted in items ending up on the floor where the VR tracking would often fail. The fix was to move to no gravity and have very high dampening of motion, so the objects would float in space for easy reach.

Occasionally some parts, when attached to each other, broke apart into writhing snakes. The solution for this was to improve the collision mesh by not relying on the mesh of the model and instead to add box, sphere and capsule colliders to enclose the model and dampen the motions to prevent run away physics.

A limitation in the authors' implementation of the attachment method meant that it was not possible to assemble the body in any possible direction and instead everything was attached from the skull down which occasionally led to frustration when the correct part would not attach if not following in the top down order. With no reasonable fix for this, we had to explain in the intervention to all participants that this could not be done.

While completing the user play testing the students were given initial instructions to use the VR controls, due to their lack of $V R$ use before this point. We observed very different behaviours in the students; some would stand perfectly still while others would move freely around the VR space. When the students started interacting with the $V R$ it became clear that there were different strategies taken to learning by each student. For example, when dealing with a bone they did not know, students used a number of distinct strategies to problem solve, these 
included: running a part over the preassembled section expecting the part to lock into place (this was perhaps to be expected), not attaching parts they did not know out of fear of failure, repeatedly questioning the developer where the part went, looking for reassurance. In contrast, others would answer the labelling questions and then try and use the names to guess where the part went, which regularly resulted in the cervical vertebrate being placed in between the hips. If a student was stubborn they would force the parts together repetitively without considering that another bone was required. This often resulted in frustration and failure. Students would often grab the nearest part which led to a bias in that they assumed the nearest part was the next bit they needed. When students recognized trends such as ball in socket joints they would quickly complete all of the ball in socket joint tasks. Quite often the discovery of a new bone position resulted in incredulity. A common example was the existence of two bones in the forearm at which the author would take away the controllers and request students feel their own arms for clarification. Similarly, students also struggled with the realization that there are two bones in the lower leg, the author postulates that this is due to a cultural representation of the skeleton having only single bones in the lower leg and forearm, which could also be a consequence of low detail models making students think the conceptual understanding of a system is simpler than it actually is.

\section{Test performance}

None of the participants had previous VR experience. Participants took on average $21.2 \pm 10.9$ minutes to complete the task in the VR platform. One participant failed to complete the VR task in its entirety. Data for the randomized pre- mid- post-skeletal system tests are shown in Figure 5. No significant difference was seen in test scores across the time points $(F(2,15.5)=2.219$, $P=0.141$ ) although an improvement in test score of $10 \pm 15 \%$ was shown following the use of the VR platform $(P=0.056)$, compared to $0 \pm 12 \%(P=0.407)$ when students studied from the set of written notes.

\section{Learning effects}

Those who participated in the study and experienced the VR task performed significantly better on the end of module examination than those students who did not $(69.1 \pm 7.7 \%$ and $52.5 \pm 18.3 \%$. respectively, $P=0.012)$ (Table 2). Those who agreed to participate in the study

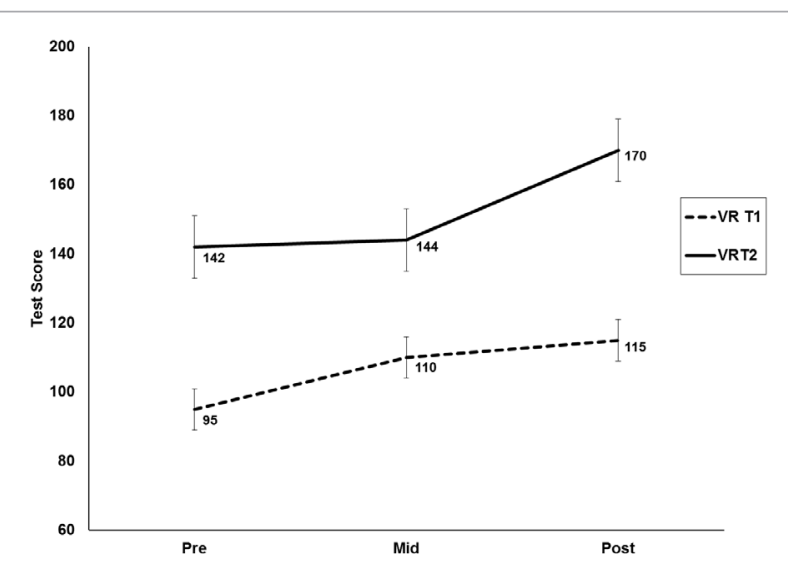

Figure 5. Skeletal system test scores at each time point of the trial. Mean values displayed ( \pm SEM).

did however perform better on all modules they studied during the same semester $(69.2 \pm 8.8 \%$ and $57.7 \pm 14.4$, respectively, $P=0.028$ ). When comparing performance on the Anatomy module with broader performance across the other modules studied, those who completed the VR task maintained their overall module average on the Anatomy module $(-0.16 \pm 10.00 \%, P=0.964)$, whereas those who did not complete the VR task performed significantly poorer on the Anatomy module than their combined average on their other modules $(-5.21 \pm 13.25 \%$, = 0.031).

\section{Questionnaire data}

Table 3 shows the responses given by participants to the questionnaire administered at the end of the module. Responses were positive with $100 \%$ of respondents $(\mathrm{N}=7)$ agreeing that virtual reality apps have a place in university education and several responses to openended questions asking for more opportunities to carry out such tasks: "I would like to use this often in various modules if possible! "; "The regular use of this", and, "I'm happy our course had this opportunity. Would be glad to participate in something like that again :)".

\section{Discussion}

The aims of this study were to investigate whether a specifically developed immersive VR platform in anatomy (Aim 1) could improve student learning and attainment in the subject area (Aim 2) and to ascertain students' thoughts and feelings about using VR in this way (Aim 3). The main finding was that although there was no statis- 
Table 2. End of module examination performance (\%).

\begin{tabular}{|l|c|c|c|c|}
\hline VR participant & $\begin{array}{c}\text { Exam mark } \\
\text { (Anatomy) }\end{array}$ & $\begin{array}{c}\text { Mean module mark } \\
\text { (5 other modules) }\end{array}$ & \% difference & Sig. $(P=)$ \\
\hline Yes $(N=9)$ & $69.1 \pm 7.7$ & $69.2 \pm 8.8$ & $-0.16 \pm 10.0$ & 0.964 \\
\hline No $(N=33)$ & $52.5 \pm 18.3$ & $57.7 \pm 14.4$ & $-5.21 \pm 13.25$ & $0.031^{\#}$ \\
\hline Sig. $(P=)$ & $0.012^{*}$ & $0.028^{*}$ & $-\cdots---\cdots---$ & $-\cdots----$ \\
\hline
\end{tabular}

${ }^{*} P$ is significant at $P<0.05$, independent samples T-test; ${ }^{~} P$ is significant at $P<0.05$, Paired samples T-test.

tically significant short-term improvement in students' understanding of the skeletal system, those who participated in the VR task performed significantly better on the end of module exam than those who did not, potentially highlighting a longer-term benefit to completion of the task.

Following the successful development of the VR application the second aim was to assess its effectiveness on student learning in both the short- and longer-term. In the short-term a non-significant improvement of $10 \pm 15 \%$ was seen in test scores following a $21.2 \pm 10.9$ minute use of the VR application. This short-term change is likely due to the nature of the immediate feedback offered in the VR application when compared to using traditional written notes $(0 \pm 12 \%$ change). The $V R$ task was procedural in nature and with the addition of labelling questions allowed students to understand both the 3D spatial relationships between the structures and the terms associated with them. Merchant et al. (2012) suggest that when tasks are procedural, merely "providing knowledge of correct response is sufficient to further guide the learners on completing the instructional task." (p. 37). The underlying reason could be that since this is a procedural task, learners are able to explore various ways of accomplishing it, benefiting their learning. In the longer-term, students who participated in the VR task performed significantly better than students on the same module who had not participated. This is unsurprising as students self-selected to participate in the study which likely led to more engaged students opting to take part. To further investigate this explanation, students' marks on the end of module examination were compared to their average mark over the other five modules they studied during the same semester. As is consistent with previous patterns in those studying Medical Engineering at this UK University, the majority of students performed worse in Anatomy than in their other modules, however, those who had participated in the VR task were able to main- tain a more consistent module mark suggesting a benefit above and beyond them being just the 'better' students. This finding is also consistent with those of Merchant et al. (2012); their meta-analysis concluded that VR based games had a similar effect on student learning whether they were assessed on knowledge gained immediately or at a later date. One potential explanation for this finding could be related to the spatial understanding required to complete the VR task. It has been suggested that VR learning environments allow learners to acquire knowledge with less cognitive effort than a more traditional learning process (Sweller, 1994; Chittaro \& Ranon, 2007) and it has been shown that 'games' in VR have the highest level of 'learning outcome gains' over simulations and virtual worlds (Merchant et al., 2012) offering potential explanation for the current study findings.

The final aim of the current study was to ascertain students' views on the developed VR application and on the use of VR in Higher Education more widely. The view of students who participated in the study was overwhelmingly positive. Students saw the benefit of using the VR application on their learning with $71.4 \%$ agreeing that participating in the virtual reality project had helped their attainment on the module with much of this attributed to VR giving "a clearer visual perception of the bones" (83.0\%) and highlighting "areas unsure of" (16.7\%). This is consistent with research suggesting that anatomy education and understanding requires 3D spatial understanding of structures and the relationships between them (Levinson et al., 2007; Preece et al., 2013; Hackett \& Proctor, 2016; Khot et al., 2017). Promisingly, $100 \%$ of students thought that VR had a place in their university education, which gives important support for the wider development of VR applications in education and the investment required as described in this paper.

In summary, the current study highlights the beneficial learning opportunity offered by immersive VR for the 
Table 3. Questionnaire responses $(\mathrm{N}=7)$.

\begin{tabular}{|c|c|c|c|}
\hline Question & \\
\hline Have you experienced virtual reality apps before? & \multicolumn{3}{|c|}{$\begin{array}{l}\text { Responses (\%) } \\
\text { No (100\%) }\end{array}$} \\
\hline $\begin{array}{l}\text { Do you feel virtual reality apps have a place in your } \\
\text { university education? }\end{array}$ & Yes (100\%) & \multicolumn{2}{|l|}{ No $(0 \%)$} \\
\hline $\begin{array}{l}\text { What (if any) benefit do you think the app had on } \\
\text { your learning? }\end{array}$ & \multicolumn{3}{|c|}{$\begin{array}{l}\text { Highlighted areas unsure of (16.7\%) } \\
\text { Gave a clearer visual perception of the bones (83.3\%) }\end{array}$} \\
\hline $\begin{array}{l}\text { Do you feel participating in the virtual reality project } \\
\text { has helped your attainment on this module? }\end{array}$ & Yes (71.4\%) & No (0\%) & Don't know (28.6\%) \\
\hline $\begin{array}{l}\text { Do you have any comments about your experience } \\
\text { of using the VR anatomy app? }\end{array}$ & $\begin{array}{l}\text { "I'm happy o } \\
\text { glad to partic } \\
\text { "It was intere } \\
\text { image of hov } \\
\text { "Needed mo } \\
\text { "It was a goo } \\
\text { tions that we } \\
\text { was in the } V\end{array}$ & $\begin{array}{l}\text { ourse had } \\
\text { te in somet } \\
\text { hg and quit } \\
\text { e bones fit } \\
\text { Dones to lea } \\
\text { xperience r } \\
\text { asked in the }\end{array}$ & $\begin{array}{l}\text { portunity. Would be } \\
\text { ke that again :" } \\
\text { t gave a clearer } \\
\text { er." } \\
\text { ut" } \\
\text { did not relate to what }\end{array}$ \\
\hline What would you like to see done differently? & \multicolumn{3}{|c|}{$\begin{array}{l}\text { "The questions in the online test did not marry up well } \\
\text { with the exercise of constructing the skeleton." }\end{array}$} \\
\hline $\begin{array}{l}\text { Are there any other areas of anatomy (or more } \\
\text { widely) that you would like to see in VR? }\end{array}$ & \multicolumn{3}{|c|}{$\begin{array}{l}\text { "I think it would be interesting to look deeper in sys- } \\
\text { tems, for example I'm expecting cardiovascular and } \\
\text { respiratory systems being pretty hard. If we would } \\
\text { have VR exercise to make content clearer, would be } \\
\text { perfect." }\end{array}$} \\
\hline $\begin{array}{l}\text { Any other comments or useful feedback you'd like to } \\
\text { offer? }\end{array}$ & \multicolumn{3}{|c|}{$\begin{array}{l}\text { "thank you :)" } \\
\text { "Great experience!" }\end{array}$} \\
\hline
\end{tabular}


study of human anatomy. The developmental process is discussed in detail, adding to the current technical support literature and aimed at supporting others to develop their own applications in this manner. Evidence is provided that using VR in this way, including elements of game, can improve students' learning in both the shortand longer-term. The current study thus concludes that students value and want to see VR as part of their Higher Education experience.

As both the VRTK tool kit was open and the anatomy database was opened this version of the project is available on the open Github for anyone to download and testing with any legally suitable copy of Unity (Available from: https://github.com/SwansealMO/Assembly).

\section{References}

Botezatu, M., Hult, H., Tessma, M.K., \& Fors, U.G.H. (2010). Virtual patient simulation for learning and assessment: Superior results in comparison with regular course exams. Medical Teacher, 32(10), 845-850, https://doi.org/10.3109/01421591003695287

Burdea, G.C., \& Coiffet, P. (2003). Virtual Reality Technology (2nd ed.), New York: John Wiley \& Sons.

BodyParts3D, Copyright 2008 ライフサイエンス統合 データベースセンター licensed by CC表示一継承

2.1 日本http://lifesciencedb.jp/bp3d/info_en/index. html\#For_repeaters https://creativecommons.org/ licenses/by-sa/2.1/jp/deed.en_US

Chittaro, L., \& Ranon, R. (2007). Web3D technologies in learning, education and training: Motivations, issues, opportunities. Computers \& Education, 49, 3-18.

Codd, A.M., \& Choudhury, B. (2011). Virtual reality anatomy: Is it comparable with traditional methods in the teaching of human forearm musculoskeletal anatomy. Anatomical Sciences Education, 4, 119-125. https://doi.org/10.1002/ase.214

Filer, T., \& Holmes, M. (2018). Using VR to increase student engagement and employability skills when teaching taxation. Retrieved on 17/01/2019 from: https://apiar.org.au/?conference-paper=using-vrto-increase-student-engagement-andemployabilityskills-when-teaching-taxation

Hackett, M., \& Proctor M. (2016). Three-dimensional display technologies for anatomical education: A literature review. Journal of Science Education and
Technology, 25, 641-654. https://doi.org/10.1007/ s10956-016-9619-3

Hariri, S., Rawn, C., Srivastava, S., Youngblood, P., \& Ladd, A. (2004). Evaluation of a surgical simulator for learning clinical anatomy. Medical Education, 38, 896-902.

Johnston, A.N.B. (2010). Anatomy for nurses: Providing students with the best learning experience. Nurse Education in Practice, 10(4), 222-226. https://doi. org/10.1016/j.nepr.2009.11.009

Khanna, R., Guler, I., \& Nerkar, A. (2016). Fail often, fail big, and fail fast? learning from small failures and $R \& D$ performance in the pharmaceutical industry. Academy of Management Journal, 59(2), 436-459. https://doi.org/10.5465/amj.2013.1109

Khot, Z., Quinlan, K., Norman, G.R., \& Wainman, B. (2013). The relative effectiveness of computerbased and traditional resources for education in anatomy. Anatomical Sciences Education, 6, 211-215. Levinson, A.J., Weaver, B., Garside, S., McGinn, H., \& Norman G.R. (2007). Virtual reality and brain anatomy: A randomised trial of e-learning instructional designs. Medical Education, 41, 495-501. https://doi. org/10.1111/j.1365-2929.2006.02694.x

Lim, K.H.A., Loo, Z.Y., Goldie, S.J., Adams, J.W., \& McMenamin, P.G. (2016). Use of 3D printed models in medical education: A randomized control trial comparing 3D prints versus cadaveric materials for learning external cardiac anatomy. Anatomical Sciences Education, 9, 213-221. https://doi. org/10.1002/ase.1573

Loftin, B., Wang, L., Baffes, P., \& Hua, G. (1988). An intelligent training system for space shuttle flight controllers. Telematics and Informatics, 5(3), 151-161. https://doi.org/10.1016/S0736-5853(88)80020-OR

McLachlan, J.C., \& Patten, D. (2006). Anatomy teaching: Ghosts of the past, present and future. Medical Education, 40, 243-253.

McMenamin, P. G. (2008). Body painting as a tool in clinical anatomy teaching. Anatomical Sciences Education, 1, 139-144. https://doi.org/10.1002/ ase.32

Merchant, Z., Goetz, E.T., Cifuentes, L., KeeneyKennicutt, W., Trina, D., \& Davis, J. (2014). Effectiveness of virtual reality-based instruction on students' learning outcomes in K-12 and higher education: A meta-analysis. Computers \& 
Education 70, 29-40. https://doi.org/10.1016/j.compedu.2013.07.033

Nanjundaiah, K., \& Chowdaporkar, S. (2012). Body painting: a tool which can be used to teach Surface Anatomy. Journal of Clinical and Diagnostic Research, 6(8), 1405-1408. https://doi.org/10.7860/ JCDR/2012/4700.2370

Nicholson, L.L., Reed, D., \& Chan, C. (2016). An interactive, multi-modal Anatomy workshop improves academic performance in the health sciences: A cohort study. BMC Medical Education, 16(7). https:// doi.org/10.1186/s12909-016-0541-4

Norman, A. (2002). The Design of Everyday Things. New York, USA: Basic Books, Inc.

Owen, N., Boston, C., Aldridge, S. Johnston, R., \& Loe, L. (2016). Validity of photogrammetric osteological analysis for sex traits of historic crania. Proceedings of 18th Annual Conference British Association for Biological Anthropology and Osteoarchaeology, 1, 65-66.

Peterson, D.C., \& Mlynarczyk, G.S.A. (2016). Analysis of traditional versus three-dimensional augmented curriculum on anatomical learning outcome measures. Anatomical Sciences Education, 9, 529-536. https:// doi.org/10.1002/ase.1612

Preece, D., Williams, S.B., Lam, R., \& Weller, R. (2013). "Let's get physical": Advantages of a physical model over 3D computer models and textbooks in learning imaging anatomy. Anatomical Sciences Education, 6, 216-224.
Satava, R.M. (1993). Virtual reality surgical simulator: The first steps. Surgical Endoscopy, 7(3), 203-205.

Seymour, N.E., Gallagher, A.G., Roman, S.A., O'Brien, M.K., Bansal, V.K., Andersen, D.K., \& Satava R.M. (2002). Virtual Reality training improves operating room performance. Annals of Surgery, 236(4), 458-464.

Sugand, K., Abrahams, P., \& Khurana, A. (2010). The anatomy of anatomy: A review for its modernization. Anatomical Sciences Education. 3(2), 83-93.

Sweller, J. (1994). Cognitive load theory, learning difficulty, and instructional design. Learning and Instruction, 4(4), 295-312. https://doi. org/10.1016/0959-4752(94)90003-5

VanPutte, C., Regan, J., \& Russo, A. (2014). Seeley's Anatomy \& Physiology (10 ${ }^{\text {th }}$ edition). New York, USA: McGraw Hill.

Vernon, T., \& Peckham, D. (2002). The benefits of 3D modelling and animation in medical teaching. Journal of Visual Communication in Medicine, 25, 142-148.

Webster, S. (2015). Anatomy in 3D. SALT Case Study at Swansea University (retrieved 16th November 2016) from: http://swansealearninglab.pbworks.com/w/ page/82063805/SALT\%20Case\%20Study\%3A\%20 \%20Anatomy\%20in\%203D

Wright, S.J. (2012). Student perceptions of an upperlevel, undergraduate human anatomy laboratory course without cadavers. Anatomical Science Education, 5, 146-157. https://doi.org/10.1002/ ase.1265 